\title{
GeV LIGHT CURVES OF YOUNG SUPERNOVA REMNANTS
}

\author{
O. Petruk ${ }^{1,2}$ (D), V. Beshley ${ }^{1}$ (D), V. Marchenko ${ }^{3}$ (D) M. Patrii ${ }^{4}$ (D) \\ ${ }^{1}$ Institute for Applied Problems in Mechanics and Mathematics, \\ 3-b, Naukova St., Lviv, UA-79060, Ukraine \\ e-mail:beshley.vasyl@gmail.com \\ ${ }^{2}$ Astronomical Observatory, \\ Ivan Franko National University of Lviv, \\ 8, Kyryla and Methodia St., Lviv, UA-79005, Ukraine \\ ${ }^{3}$ Astronomical Observatory, Jagiellonian University, \\ Orla 171, 30-244, Cracow, Poland \\ ${ }^{4}$ Faculty of Physics, Ivan Franko National University of Lviv, \\ 8, Kyryla and Methodia St., Lviv, UA-79005, Ukraine
}

(Received 06 May 2020; in final form 23 May 2020; accepted 27 May 2020; published online 18 September 2020)

\begin{abstract}
Observational data from the Fermi Gamma-ray Space Telescope are analyzed with the goal in mind to look for variations in the $\gamma$-ray flux from young shell-like supernova remnants. A uniform methodological approach is adopted for all SNRs considered. G1.9+0.3 and Kepler SNRs have not been detected. The light curves of Cas A and Tycho SNRs are compatible with the steady $\mathrm{GeV}$ flux during the recent ten years, as also X-ray and radio fluxes. Less certain results on SN1006 and SN1987A are discussed.
\end{abstract}

Key words: supernova remnants, gamma-rays, light curves.

DOI: https://doi.org/10.30970/jps.24.3903

\section{INTRODUCTION}

Almost two decades passed since the first view of a shell-like supernova remnant (SNR) in $\gamma$-rays: HEGRA stereoscopic system has detected a flux from Cas A [1]. The next generation of the Cherenkov telescopes as well as the Fermi observatory advance our knowledge about $\gamma$-ray emission from SNRs. At present, there are 12 firm confirmations of $\mathrm{TeV}$ gamma-rays from the shelllike galactic SNRs: 9 observed by H.E.S.S. [2] and 3 by northern Cherenkov observatories [4-6]. In addition to this, 8 H.E.S.S. sources are composite SNRs (consisting of pulsar and SNR shell), and almost 20 H.E.S.S. sources are SNR candidates $[2,3]$. The results of the systematic search for SNRs in a softer $\mathrm{GeV}$ photon energy range are presented in the Fermi SNR catalogue [7]. ${ }^{1}$ There are 30 SNRs, and 14 possible SNRs have been listed in this source.

A useful tool for those interested in the high-energy emission from SNRs is the catalogue first introduced in $[8] .^{2}$

All $\gamma$-ray observations of SNRs are a clear demonstration that SNR shocks are able to accelerate cosmic-rays (CRs) to multi-TeV energies. The shapes of the spectra give a deeper insight into related physics. In particular, detection of the high-energy cut-off at the photon energies $<10^{14} \mathrm{eV}$ in the $\gamma$-ray spectrum of Cas A [9] and other SNRs is somehow unfortunate: it demonstrates that at least these SNRs do not accelerate cosmic rays to the

\footnotetext{
1 https://fermi.gsfc.nasa.gov/ssc/data/access/lat/1st_SN R_catalog/

2 http://snrcat.physics. umanitoba.ca/
}

energies of the knee in the CR spectrum. The low-energy portions of $\gamma$-ray spectra in IC443 and W44 appear to be more impressive: they are the first observational proofs that protons accelerated (or re-accelerated) in the SNR shocks [10].

In contrast to SNRs, no supernova has been observed in $\gamma$-rays (except for the long GRBs which are believed to arise from the core-collapse event). Therefore, there is also no observational clue of how the $\gamma$-ray light curves of these explosive events look like.

There is a sign of the temporal evolution of the $\gamma$-ray spectra from SNRs - on a time-scale of the SNR lifespan: spectra of the young, middle-age and old SNRs seem to group separately [Fig. 6 in 11]. Such a property reflects mostly the cardinal changes in SNRs' properties relevant for different evolutionary stages.

Time evolution of the $\gamma$-ray emission from the shells of young SNRs could be important as an insight into the physics of the time-dependent particle acceleration at the fresh shocks. Therefore, the remnant of SN1987A would be a promising source. An interesting result related to the possible detection of $\mathrm{GeV} \gamma$-rays from SN1987 has been published recently in [12]. Other historical SNRs are interesting in this respect as well.

The goal of the present paper is to look for the time variations in the $\mathrm{GeV} \gamma$-ray fluxes from young SNRs.

In particular, we analyse, under a uniform approach, $\gamma$-rays from the historical supernova remnants, aged up to a thousand years: SN1987A, G1.9+0.3, Cas A, Kepler, Tycho, SN1006. Our primary focus is on the shock particle acceleration, therefore, we are interested in shell-like SNRs only. Therefore, the pulsar-dominated historical SNRs, Crab nebula and 3C58, are not considered in the present paper. 


\section{DATA ANALYSIS}

The standard binned likelihood analysis with gtlike $e^{3}$ tool provided by Fermi Science Tools is used for all SNRs presented in this paper. For our analysis we use the latest release of the LAT Pass 8 data and consider a period that covers 10 years of observation (from August 2009 to August 2019). The region of interest (ROI) is centered on a given object and has radius $14^{\circ}$. All events with a zenith angle greater than $90^{\circ}$ (see the LAT instrument team recommendation) are ignored. The latest version of the Fermi Science Tool with the P8R3_CLEAN_V2 Instrumental Response Function is used.

The energy dispersion in the data analysis which is particularly important below $1 \mathrm{GeV}$ is taken into account. The upper limits are calculated with the UpperLimits python module; they are on the $95 \%$ confidence level.

We model ROI taking into account all known neighbouring and background sources, namely, all sources from the 4FGL catalogue (gll_psc_v19.fit) as well as both the Galactic diffuse background gll_iem_v07.fits and extra-galactic isotropic background iso_P8R3_CLEAN_V2_v1.txt.

The spectra of the neighbouring sources are the same as in the 4FGL catalogue. The normalisation parameter is free for all objects in ROI; other parameters are fixed. We also include the sources with fixed parameters which are within the annulus of the size from $14^{\circ}$ to $28^{\circ}$ outside of the ROI region. All sources which appears to have $T S<0$ were excluded from consideration.

In the present paper we analyse six young SNRs. Three of them are listed in the 4FGL catalogue $[19]^{4}$, namely, Cas A (4FGL J2323.4+5849), Tycho (4FGL J0025.3+6408) and SN1006 (4FGL J1503.6-4146).

Therefore, we used for each of these SNRs the model with the PLSuperExpCutoff 2 spectrum $^{5}$ with a free normalization. ${ }^{6}$ The PLSuperExpCutoff2 model was adopted because 1) it is used in the Fermi catalogue and 2 ) this model is rather general: i) it restores the cutoff if it is in the spectrum; ii) if the break energy is high then this model behaves like a simple power-law (Tycho case); iii) this model cannot be distinguished from the broken power-law (eventually, the case of Cas A) in the photon energy range which we consider.

As to the other three SNRs, SN1987a, G1.9+0.3 and Kepler, which are not included in the catalogue, we adopt a model with the power-law spectrum with free normalization and the spectral index 2.1 [12], 2.6 [15], 2.0 (lower index in [20]) respectively. This model is used in order to reduce the number of free parameters in the cases

\footnotetext{
3 https://fermi.gsfc.nasa.gov/ssc/data/analysis/

4 https://fermi.gsfc.nasa.gov/ssc/data/access/lat/8yr_ca talog/

${ }^{5}$ https://fermi.gsfc.nasa.gov/ssc/data/analysis/scitools /source_models.html

6 We tried also models with a free exponential factor; the results were amost the same as with the factor from the 4FGL catalogue
}

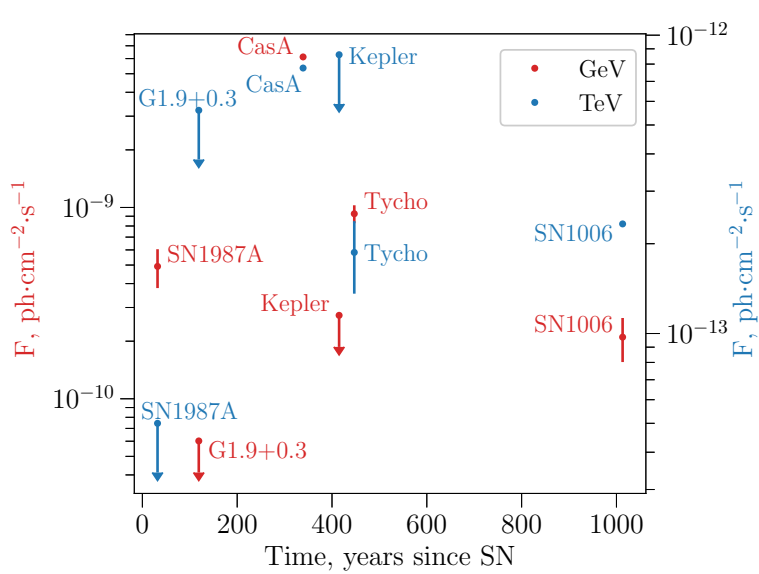

Fig. 1. Flux versus age for young historical shell-like SNRs. Red data points (the left axis) represent the $\mathrm{GeV}$ fluxes in the photon energies 1-100 GeV and for 10 years of observations. The values of the test statistics of our analysis for the red points: SN1987A $(T S=36), \mathrm{G} 1.9+0.3(T S \approx 0)$, CasA $(T S=3642)$, Kepler $(T S=4.9)$, Tycho $(T S=132)$, SN1006 $(T S=23)$. Errors are at the $1 \sigma$ level. Blue data points (the right axis) show the $\mathrm{TeV}$ fluxes (for photon energies $>1 \mathrm{TeV}$ ). References for the blue points: SN1987A [21]; G1.9+0.3 [22]; Cas A [23]; Kepler [20]; Tycho [6]; SN1006 [24].

which have low significance and an unclear shape of the spectrum in the $\mathrm{GeV}$ range.

\section{RESULTS}

\section{A. GeV fluxes}

First, we checked if our methodology reproduces known measurements.

Table 1 presents the list of the historical shell-like SNRs with the $\gamma$-ray fluxes from the literature (sixth column). The fluxes calculated with our approach (in the seventh column) correspond to the same observation period and the same photon energy range as in the reference. The differences are within the errors and appear because we used the last data release of (P8R3) and the most recent source and background models.

Then, we performed a uniform analysis of the Fermi data for all these SNRs. At the beginning, we have measured the fluxes in the photon energy range $1-$ $100 \mathrm{GeV}^{7}$ for 10 years of observations (27 August 2009 27 August 2019) and plotted them versus the SNR age (Fig. 1 red points). GeV fluxes are shown on this figure for the objects with the test statistics $T S>20$; the upper limits are shown for the smaller $T S$.

\footnotetext{
7 Considering that the fluxes of young SNRs below $1 \mathrm{GeV}$ are typically low [11], we decided to skip the $0.1-1 \mathrm{GeV}$ range, in order to have a higher validity of the results.
} 


\begin{tabular}{|c|c|c|c|c|c|c|c|}
\hline SNR & $\begin{array}{l}\text { SN } \\
\text { event } \\
\text { year }\end{array}$ & Ref & $\begin{array}{l}\text { energy } \\
\text { range } \\
\mathrm{GeV}\end{array}$ & $\begin{array}{l}\text { observational } \\
\text { data from } \\
\text { the period }\end{array}$ & $\begin{array}{l}\text { flux or } \\
\text { upper limit } \\
\text { (reference) }\end{array}$ & $\begin{array}{l}\text { flux or } \\
\text { upper limit } \\
\text { (present paper) }\end{array}$ & units \\
\hline SN1987A & 1987 & {$[12]$} & $1.0-100$ & $08.2016-12.2018$ & $8.3 \pm 2.4$ & $9.7 \pm 2.7$ & $10^{-10} \mathrm{ph} \mathrm{cm}^{-2} \mathrm{~s}^{-1}$ \\
\hline $\mathrm{G} 1.9+0.3$ & $1900^{(1)}$ & {$[15]$} & $0.2-300$ & $08.2008-06.2014$ & 4.43 & 0.22 & $10^{-9} \mathrm{ph} \mathrm{cm}^{-2} \mathrm{~s}^{-1}$ \\
\hline $\operatorname{Cas} \mathrm{A}^{(3)}$ & $1680^{(2)}$ & {$[16]$} & $0.1-100$ & $08.2008-04.2012$ & $6.2 \pm 0.4$ & $5.8 \pm 0.3$ & $10^{-11} \mathrm{erg} \mathrm{cm}^{-2} \mathrm{~s}^{-1}$ \\
\hline Kepler & 1604 & - & $0.1-100$ & 08.2009-08.2019 & - & 2.73 & $10^{-10} \mathrm{ph} \mathrm{cm}^{-2} \mathrm{~s}^{-1}$ \\
\hline Tycho & 1572 & {$[17]$} & $0.4-100$ & $08.2008-05.2011$ & $3.5 \pm 1.1$ & $2.6 \pm 0.5$ & $10^{-9} \mathrm{ph} \mathrm{cm}^{-2} \mathrm{~s}^{-1}$ \\
\hline SN1006 & 1006 & [18] & $0.5-500$ & $08.2008-12.2018$ & $5.9 \pm 1.7$ & $5.8 \pm 1.2$ & $10^{-10} \mathrm{ph} \mathrm{cm}^{-2} \mathrm{~s}^{-1}$ \\
\hline
\end{tabular}

(1) [13]; (2) [14]; (3) note that the energy fluxes are given for this SNR

Table 1. GeV fluxes of the historical shell-like SNRs. Comparison with previous measurements. In cases of G1.9+0.3 and Kepler, the upper limits are presented.

One may notice that the GeV flux from SN1987A calculated over the 10-years period (Fig. 1) is almost two times smaller than that obtained by the same approach from the observations during 28 months in years 2016-2018 (Table 1). This discrepancy is discussed in Sect. IV B.

The GeV signal from Kepler SNR has $T S=4.9$, therefore, one cannot claim its detection in the data collected by Fermi LAT during 10 years of observation. The upper limit for the total photon flux is $2.7 \times 10^{-10} \mathrm{ph} \mathrm{cm}^{-2} \mathrm{~s}^{-1}$. G1.9+0.3 is not detected either (TS is close to zero) with the upper limit $6.0 \times$ $10^{-11} \mathrm{ph} \mathrm{cm}^{-2} \mathrm{~s}^{-1}$. Kepler SNR is within ROI for G1.9 +0.3 (the distance from the center is about $7^{\circ}$ ). Its test statistics is larger than zero, therefore, we included Kepler SNR in the model for G1.9+0.3, with the powerlaw spectrum with free normalization and the spectral index given at the end of Sect. II.

Looking at Fig. 1, we cannot infer any meaningful hint about an evolution of the GeV $\gamma$-ray flux in young SNRs. Different SN types and their expansion in different ambient conditions are rather more important in the determination of the individual SNR flux than eventual similarities in the early evolution of the particle acceleration.

$\mathrm{TeV}$ fluxes appear to behave in a similar way to the $\mathrm{GeV}$ fluxes, as shown in Fig. 1 for Cas A, Tycho and SN1006. This is not a surprise because $\mathrm{GeV}$ and $\mathrm{TeV}$ fluxes are parts of the broader spectra of the same SNRs. Interestingly, $\mathrm{TeV}$ fluxes for Cas $\mathrm{A}$ and Tycho are lower than the $\mathrm{GeV}$ fluxes, in contrast to SN1006 where the $\gamma$-ray spectrum is harder.

\section{B. Light curves}

Four young SNRs have rather a high detection significance in the Fermi LAT data for 10 years of observations. Therefore, we have analysed fluxes of these SNRs in the consecutive 2-year time intervals. The results are shown in Fig. 2. For this plot, the upper limits were calculated if the test statistic for a given point is less than 4 .

Such a plot is more informative in respect of the temporal variation in the $\gamma$-ray emission of young SNRs than Fig. 1. Each point in the light curves for Cas A and
Tycho has significance above $4 \sigma$. Four out of five points for the region of SN1987A are above $3 \sigma$. Trend for SN1006 is less significant.

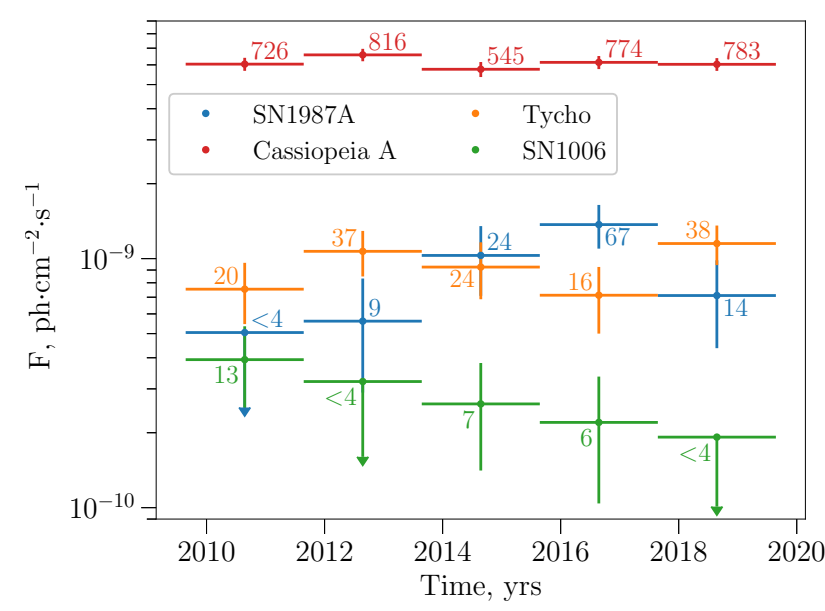

Fig. 2. Flux evolution for four supernova remnants in the photon energy range $1-100 \mathrm{GeV}$. One point corresponds to 2 years of Fermi LAT observations. The values of TS are shown near the data points.

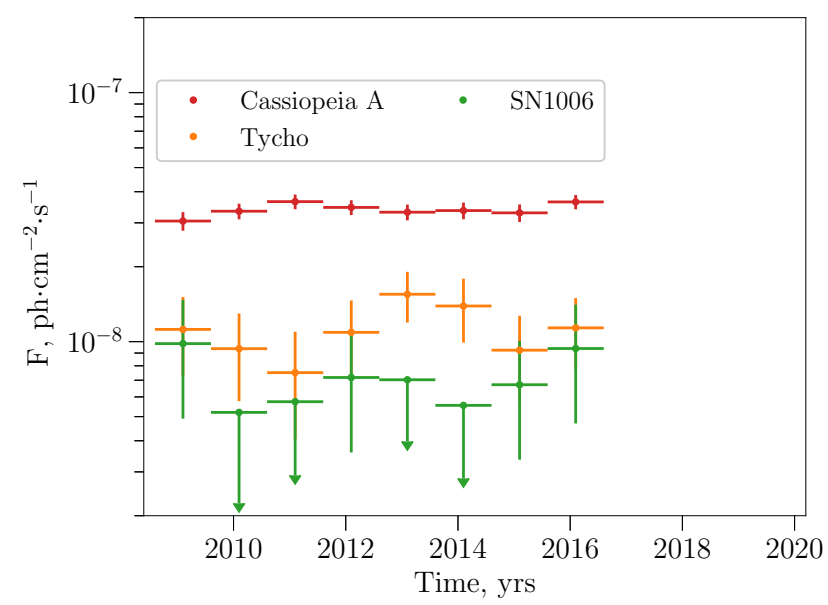

Fig. 3. Light curves from 4FGL with the one-year intervals. Photon energy range $0.1-100 \mathrm{GeV}$; upper limits are at the $95 \%$ confidence level. 
Light curves for Cas A and Tycho in $\mathrm{GeV} \gamma$-rays are compatible with the constant emission over the recent 10 years. Variability of SN1987A and SN1006 is discussed in Sect. IV D and IV E.

\section{DISCUSSION}

\section{A. Comparison with 4FGL catalogue}

Changes in the flux are analysed in the forth Fermi LAT catalogue [19]. There are variability plots as well as variability indices (see Sect.3.6 in [25] for the definition of the index $T S_{\mathrm{var}}$; the source is considered variable at the $99 \%$ confidence level if $\left.T S_{\text {var }}>41.6\right)$. Low variability indices for Cas A, Tycho and SN1006, namely 4.27, 4.02 and 3.32, support the conclusion about steady fluxes from these sources over the period of observations.

Fig. 3 summarizes the data from 4FGL (with the 1year time intervals) which are available till 2016 August only.

There are nice correlations with our Fig. 2 in the shapes of the light curves for Cas A and Tycho which are detected with high significance (amplitudes differ due to different photon energy ranges).

\section{B. Comparison of the overall and the average fluxes}

It is instructive to compare the $\mathrm{GeV}$ flux derived from the 10-year observation period with the average one calculated with the fluxes obtained from the 2-year intervals (Table 2). The two numbers correspond to each other for Cas A and Tycho SNR, which have high values of $T S$. This confirms the mutual correctness of the method adopted. The coincidence is better in Cas A and the reason is obviously the very good statistics which ensures high vaidity of the results for this SNR. An average flux from SN1006 may be calculated without intervals with only the upper limits, i.e. only from points 3 and 4 in Fig. 2. The average value is somehow higher than the flux derived from the data from the 10 years. The flux calculated over an extended period containing intervals of quite low statistical significance (with upper limits or small $T S$ ) is lower than that calculated excluding these intervals. The situation is similar for SN1987A. The 10-year flux is lower than the average (see the first line in Table 2) because the first time interval in Fig. 2 for this SNR is represented by the upper limit.

The second line in Table 2 is calculated for SN1987A excluding the interval with the upper limit. The overall flux is now higher, to the level that its $1 \sigma$ range intersects with the $1 \sigma$ range of the average flux. However, it is again lower than the average.

This situation could be, as in the cases above, due to the low significance of the second or the last (or both) points in Fig. 2, which have $T S=9$ and 14 respectively, i.e. the signal for these points is at the level about $3 \sigma-4 \sigma$ that is below the certain detection ( $5 \sigma$ threshold).

\begin{tabular}{llllc}
\hline \hline SNR & \multicolumn{2}{c}{$\begin{array}{l}\text { data from } \\
\text { the period Fig. 1 }\end{array}$} & $\begin{array}{l}\text { average } \\
\text { flux for } \\
\text { Fig. 2 }\end{array}$ & $\begin{array}{l}\text { No of points } \\
\text { in Fig. 2 used } \\
\text { for the average }\end{array}$ \\
\hline SN1987A & $2009-2019$ & $4.92 \pm 1.13$ & $9.16 \pm 2.85$ & $2-5$ \\
SN1987A & $2011-2019$ & $5.94 \pm 1.30$ & $9.16 \pm 2.85$ & $2-5$ \\
Cas A & $2009-2019$ & $61.2 \pm 1.70$ & $61.1 \pm 3.70$ & $1-5$ \\
Tycho & $2009-2019$ & $9.27 \pm 1.00$ & $8.44 \pm 2.18$ & $1-5$ \\
SN1006 & $2009-2019$ & $2.10 \pm 0.54$ & $2.92 \pm 1.26$ & $3-4$ \\
\hline
\end{tabular}

Table 2. Comparison of the overall (from Fig. 2) and the average (of the time periods from Fig. 2) GeV fluxes of the four SNRs. Energy range is $1.0-100 \mathrm{GeV}$; units are $10^{-10} \mathrm{ph} \mathrm{cm}^{-2} \mathrm{~s}^{-1}$; periods are switched on August 27

\begin{tabular}{lcc}
\hline ObsID & Start date [UT] & Exposure [ks] \\
\hline \multicolumn{3}{c}{ Cas A } \\
\hline 4638 & $2004-04-14$ 19:47:55 & 164.53 \\
9117 & $2007-12-05$ 22:00:54 & 24.84 \\
10935 & $2009-11-02 ~ 22: 16: 52$ & 23.26 \\
14229 & $2012-05-1509: 15: 11$ & 49.09 \\
18344 & $2016-10-21$ 16:58:44 & 25.75 \\
19605 & $2018-05-1516: 06: 34$ & 49.41 \\
\hline \multicolumn{3}{c}{ Tycho } \\
\hline 3837 & $2003-04-2901: 59: 47$ \\
7639 & $2007-04-23$ 02:18:40 & 145.6 \\
10095 & $2009-04-23$ 21:27:53 & 173.37 \\
15998 & $2015-04-22$ 22:19:05 & 146.98 \\
\hline \multicolumn{3}{c}{ SN1006 } \\
\hline 9107 & $2003-04-0806: 33: 03$ \\
3838 & $2008-06-2414: 04: 29$ & 20.13 \\
\hline \hline
\end{tabular}

Table 3. Observation log for the analysed Chandra data

\section{Comparison with X-rays}

Are the $\gamma$-ray flux variations for these SNRs similar to the evolution of the non-thermal emission in the X-ray band?

To answer this question, we have analysed X-ray emission from small regions containing the forward shock where the non-thermal emission dominates the thermal one.

We have selected several Chandra observations of three SNRs performed since 2003 (see Table 3 for details). After choosing a region, all the observations containing this region were processed; the region was shifted between different observation ID in accordance to the SNR expansion ${ }^{8}$ to ensure the measurement of the flux variation from the same portion of the shock.

\footnotetext{
8 The expansion is tracked by creating images (see below) from different epochs of observations and moving the region in a way to cover the same pattern (which shifts somehow between observations) in the same way.
} 
The analysis was carried out using the software package CIAO 4.11 [26] and the calibration database CALDB 4.8.3. Before the analysis, the data were reprocessed using the chandra_repro script, following the standard recommendations of the CIAO analysis threads.

For the spectral analysis, we used the Sherpa fitting application [27]. After extracting the source and background spectra, the background spectrum was subtracted and the fitting was performed for the grouped spectra with the minimum signal-to-noise ratio 3 .
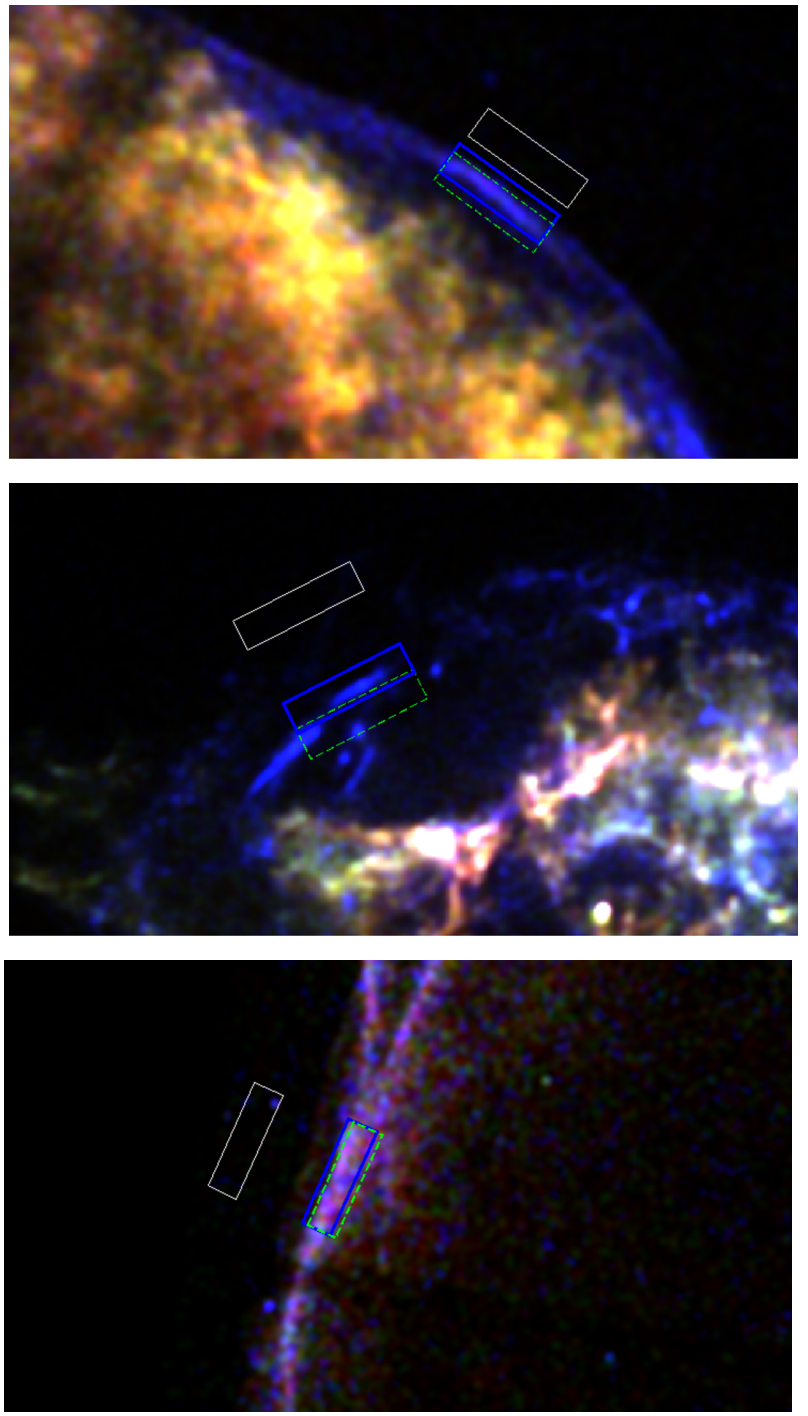

Fig. 4. Images of the region around the forward shock in SNRs: Tycho (top, obsID 15998, 22 April 2015), Cas A (middle, obsID 19605, 15 May 2018), SN1006 (bottom, obsID 9107, 24 June 2008). Colors: 1.7-2.1 keV (red, Si line), 2.3$2.6 \mathrm{keV}$ (green, S line), 4.0-6.0 keV (blue, non-thermal). The blue rectangle marks the region where the flux is measured and the white one shows the region for the background emission. Their locations correspond to the time of observation presented. The green rectangle corresponds to the location of the same shock region in 2003 (Tycho), 2004 (Cas A), 2000 (SN1006) year. The differences between the green and blue rectangles are due to the SNR expansion.

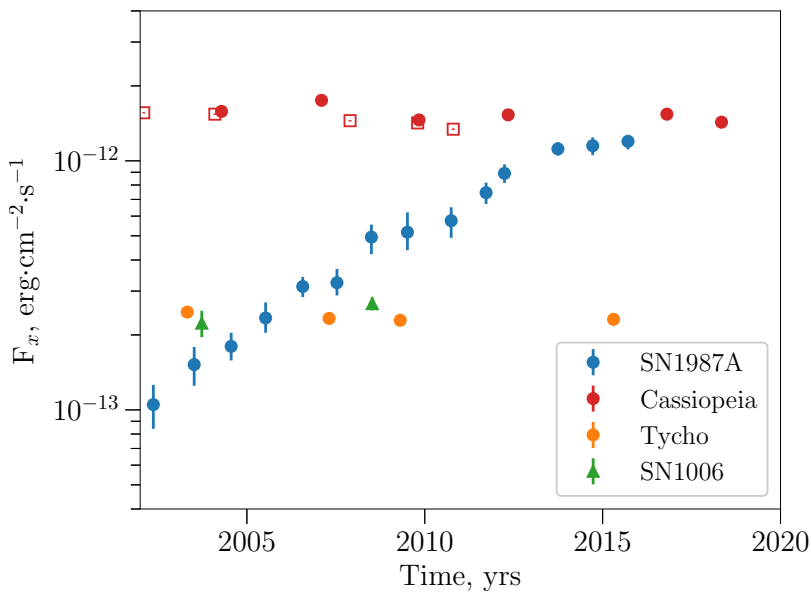

Fig. 5. Evolution of the X-ray fluxes from the shock regions (shown in Fig. 4) for Cas A, Tycho, SN1006 in the photon energy range 3-7 keV. Colors are the same as in Fig. 2. Errors represent $90 \%$ confidence interval; they are smaller than the dot sizes in some cases. Fluxes for SN1987A are from the whole SNR and for the photon energies $3-8 \mathrm{keV}$ [28]. Open squares represent the $\mathrm{X}$-ray flux from the whole Cas $\mathrm{A}$ in $4.2-6 \mathrm{keV}$ range from [29], multiplied by 0.01 .

For spatial analysis, the data were merged and binned with a binning factor of 1 , which corresponds to the original Chandra pixel size of 0.492 arcsec.

For the estimation of the flux in the source regions of Chandra's data with the corresponding background regions we used the srcflux tool from CIAO software. The flux was calculated using a model dependent estimate, where as a model we used the simple absorbed power law xsphabs*xspowerlaw.

In order to visualise the differences in the spatial structures of the regions around the forward shock in SNRs in different X-ray energy bands, we have used the three-color capabilities of the SAOImageDS9 program, where data in the three different energy bands were loaded into RGB frame and highlighted in appropriate colors (Fig. 4). The images of the selected observations were smoothed a bit with 2D Gaussian to improve visual appearance. Actually, the images in colour were used to choose a region around the forward shock where the hard $\mathrm{X}$-ray emission dominates.

The evolution of the hard X-ray fluxes extracted from the shock regions in Cas A, Tycho and SN1006 (Fig. 4) are shown in Fig. 5. The X-ray light curves for these SNRs demonstrate that the fluxes are almost steady. This is in agreement with the evolution of $\gamma$-rays from Cas A and Tycho.

In order to quantify the level of possible variations in the X-ray band, let us consider the results from [29]. The authors of this paper found that the overall X-ray emission from Cas $\mathrm{A}$ in the photon energy range $4.2-6.0 \mathrm{keV}$, i.e. the hard bremsstrahlung only (which contains both thermal and nonthermal $\mathrm{X}$-rays), declines with the rate $\sim 1.5 \% /$ yr. Their data for the whole SNR are shown in Fig. 5 by open squares. Our points (filled circles), which represent only a small region around the shock emitti- 


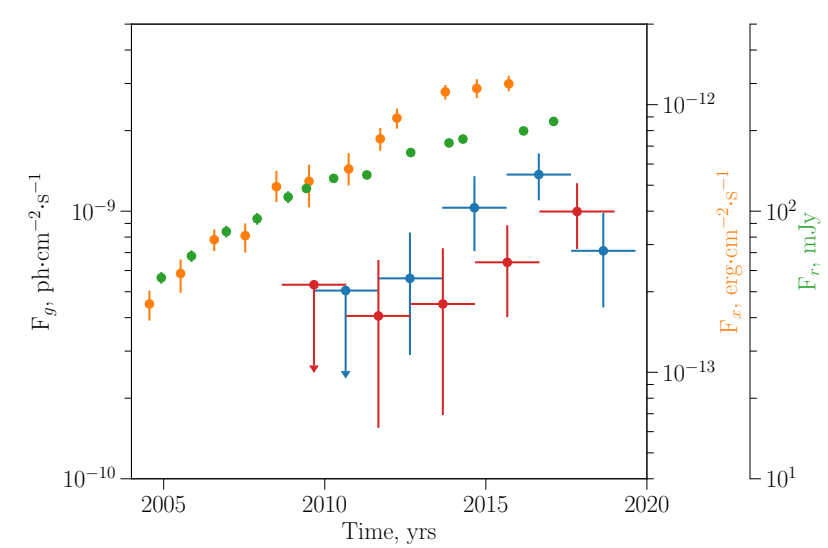

Fig. 6. Radio (green), X-ray (orange) and $\gamma$-ray (blue and red) fluxes from the region of SN1987A. Radio data for 8.6 $\mathrm{GHz}$ are from [36] till day 8014 and from [37, Table 2] for later times. X-ray data in 3-8 keV are from [28, Table 1]. Red crosses correspond to our calculations for the model from [12]; blue crosses represent our model.

ng mostly nonthermal X-rays, follow generally the same trend, although have a somehow larger spread and cover a longer time period.

The two data points in Fig. 5 for SN1006 support the steady X-ray synchrotron emission from the northeastern limb in this SNR found in [30]. The decreasing trend in the $\gamma$-ray flux evolution from SN1006 (Fig. 2) has quite low confidence.

The radio evolution of Cas A exhibits a flux decrease with the rate $\approx 0.8 \% / \mathrm{yr}[31,32]$, which may be visible on the time-scale of $\sim 50 \mathrm{yr}$. The visibility of the decreasing trend is questionable over the ten-year time interval: the flux density at $74 \mathrm{MHz}$ was $19.6 \pm 0.7 \mathrm{kJy}$ in 1997 and $17.0 \pm 2.3 \mathrm{kJy}$ in 2006 [31]. The radio flux from Tycho SNR behaves in a similar fashion; the decrease rate was estimated as $0.4 \pm 0.5 \% / \mathrm{yr}[33]$.

For the sake of comparison, in Fig. 5, we have also shown the variation in the hard X-ray flux from SN1987A, which is thermal in nature [34]. This SNR is discussed in more detail in the next section.

\section{SN1987A}

Our results on $\gamma$-rays from SN1987A are not so solid as for Cas A and Tycho. The main negative is the presence of bright sources nearby [Fig. 3 and 4 in 35]. The contribution of these sources to the emission in the location place of SN1987A has to be removed in order to estimate the flux from the SN1987A region. The results depend critically on the choice of these sources and their models: the fewer one subtracts, the more remain as residual and could be thought of as a 'signal' from SNR.

SN1987A was not previously detected in deep observations of Large Magellanic Cloud either in $\mathrm{GeV}$ [35] or in $\mathrm{TeV}$ [21] photons. In contrast, the authors of [12] used a recent data release and accurately modelled other sources in order to try to uncover the emission from
SN1987A. After removing the contribution from known sources, the authors found some remaining emission which may be interpreted as $\gamma$-rays from SN1987A.

We confirm the results of the paper [12] though our models somehow differ. The differences consist in a shift of the observation periods, in the source catalogue (we have used 4FGL instead of FL8Y), in the background emission model (we adopt gll_iem_v07.fits with iso_P8R3_CLEAN_V2_v1.txt instead of gll_iem_v06.fits with iso_P8R3_CLEAN_V2.txt. It is worth noting that we have also repeated the data analysis on SN1987A with (.xml file) sent us by D.Malyshev (i.e. with their model and setup). With this model, we have reproduced their results, including the light curve (Fig. 6 red crosses, cf. Fig. 1 in [12]).

Our analysis detects some flux in the region of SN1987A after removing the emission from the background and nearby sources, with significance $6 \sigma$, in the data collected by the Fermi observatory during 10 years till the end of August 2019. The variation of this flux in time is shown in Figs. 2 and 6 by the blue crosses.

Though the origin of these $\gamma$-rays (attribution to SN1987A) and even their detectability may in principle be questioned (because it depends on the assumed level of emission from the neighbouring sources and background), let us look at one feature in our results. Our light curve (blue in Fig. 6) generally agrees with the trend from [12] model (red in Fig. 6): the flux from the SN1987A region seems to increase with time. However, there is a difference in the last data point. In this source, the last point is in line with the brightening while in our case the flux drops. (We would like to note that the period reflected by the last data point in [12] is August 2016 - December 2018 while in the present paper it is August 2017 - August 2019.) There is a $0.28 \%$ chance that this break is random if the true trend consists in the brightness increase extrapolated from 2011-2017 yrs; this corresponds to $3.2 \sigma$ significance, that is not strongly decisive. We cannot therefore rule out that the difference between the results, in particular, the break, is unphysical. The low statistics that remained after the elimination of the background fluxes marks this break by the low significance and is quite sensitive to what we actually eliminate. In order to look deeper, we compared the lists of sources involved in the analysis and found that dozens of those which have been removed from the model in [12] because of the negative TS, have positive TS and remained in our model; and vice versa.

The slope of the $\gamma$-ray flux evolution generally agrees with the X-ray and radio light curves (Fig. 6). It should be noted that the X-rays from SN1987A are thermal in nature [34] and increase in the flux after $2011 \mathrm{yr}$ is related to the influence of the equatorial ring [34]. Interestingly, such manifestation is absent from the radio data [38]: green data points in our Fig. 6 do not follow the orange data points [see also Fig. 10 in 36].

May the comparison of the light curves in different bands (Fig. 6) suggest a hint about a physical reason for the $\gamma$-ray break? Namely, the correlations between different bands may be a sign of some physical process 
responsible for the break, and thus it is not a statistical fluctuation. In particular, could the break in the $\gamma$-ray flux be linked to changes in the acceleration process? Why then the radio emission does not show a similar break? Unfortunately, there are no definitive hints from this plot about a physical reason for the $\gamma$-ray break.

There is evidence that the forward shock in SN1987A is leaving the dense equatorial ring [28, 39]. This could be a reason for the break if the $\gamma$-rays are hadronic; at earlier times the high-density ring has enough target protons for interactions with protons accelerated by the shock.

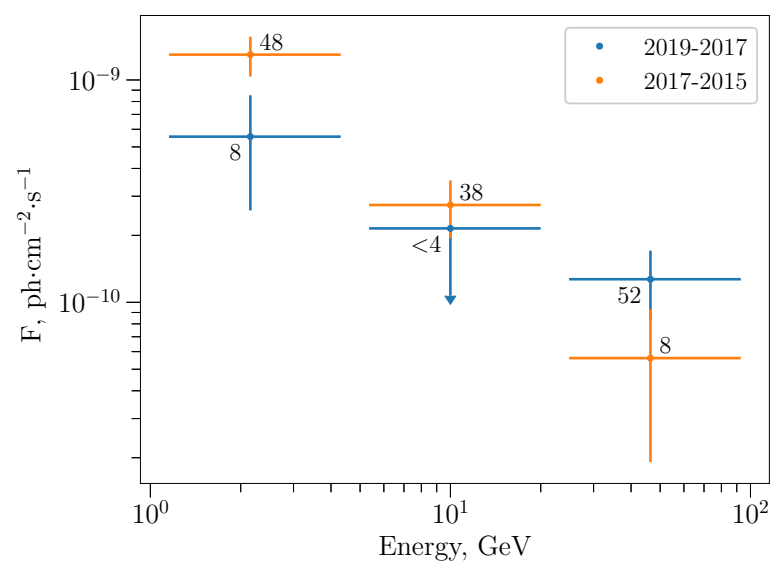

Fig. 7. Spectra of the $\mathrm{GeV}$ emission from the region of SN1987A location from two time intervals corresponding to the last two blue crosses in Fig. 6 .

One can wonder if there are essential differences between the spectra of the SN1987A region from the two periods in the observational data shown by the two last blue crosses in Fig. 6. In order to obtain these spectra, considering the low statistics, we performed a data analysis for each spectral point separately (as an independent fluxe, not with the common tool bdlikeSED.py). The spectra are shown in Fig. 7. It might be speculated that the slope of the spectrum changes between the two time intervals and the break is due to the emission decrease in the $1-5 \mathrm{GeV}$ range.

In order to make one more check, we calculated the flux from SN1987A using the observational data up to May 12, 2020. Unfortunately, there are only the upper limits in both models for this ultimate time interval. Namely, the model from [12] set it up at $4.47 \times 10^{-10} \mathrm{ph} \mathrm{cm}^{-2} \mathrm{~s}^{-1}$ with $T S=0.01$ (the period from Jan 1, 2019); it could be a sign of the break also in the red-cross trend in Fig. 6. However, the upper limit for our model is at $1.02 \times 10^{-9} \mathrm{ph} \mathrm{cm}^{-2} \mathrm{~s}^{-1}$ with $T S=1.6$ (the period from Sept 1, 2019), above the flux designated by the last blue cross. Though the upper limits support the break, the pure statistics keeps us in the unclear situation.

\section{E. SN1006}

The situation with the GeV emission from SN1006 is even less clear than in the case of SN1987A. Our estimate of the signal significance is $4.8 \sigma$ while the typically accepted value for 'detection' is at least $5 \sigma$. This is similar to those in the previous publications. This SNR was found with the detection significance $4.7 \sigma$ in [40]. An updated analysis by the same authors gave $4.5 \sigma$ for $\mathrm{NE}$ and $4.8 \sigma$ for the SW parts of the remnant [18], both below $5 \sigma$. The authors of [18] have also calculated the variability index [Sect. 3.6 in 25] for the NE and SW regions and found no significant long-term variations there.

If one plays a bit with source models then one can find a model which gives better TS: the authors of [41] reported significance between $5.3 \sigma$ and $5.9 \sigma$ depending on the source model. We have used standard models for all SNRs which we analysed in the present paper, namely, the source models from the 4FGL catalogue.

The ratio of the surface brightness between different regions of the SN1006 map in different photon energy bands may shed light on some properties of SNR [42]. In particular, under the assumption that $\gamma$-ray emission from SN1006 is the result of the inverse-Compton scatterings, the ratios of the brightness between the two limbs in the radio $\mathcal{R}_{\mathrm{r}}$ and in $\mathrm{GeV} \gamma$-rays $\mathcal{R}_{\gamma}$ may be used to see whether the magnetic field strengths $B$ are similar in the these limbs:

$$
\mathcal{R}_{\mathrm{B}}=\left(\mathcal{R}_{\mathrm{r}} / \mathcal{R}_{\gamma}\right)^{2 /(s+1)}
$$

where $\mathcal{R}_{\mathrm{B}}=B_{\mathrm{NE}} / B_{\mathrm{SW}}$ and $s$ is the radio spectral index. The ratio is $\mathcal{R}_{\mathrm{r}}=1.0$ in radio [42]. Table 4 shows the $\mathrm{GeV}$ fluxes from the NE and SW parts of SN1006 as estimated in the two publications. Their ratio (NE to $\mathrm{SW})$ is $\mathcal{R}_{\gamma}=7.0 \pm 3.5$ [41] or $\mathcal{R}_{\gamma}=0.80 \pm 0.53$ [18]. The two results are quite different and we cannot draw any conclusion except that, in the second result, the fluxes from the two regions have similar significance and they are compatible with the same magnetic field strength in both limbs.

\begin{tabular}{|c|c|c|c|}
\hline $\begin{array}{l}\text { SNR } \\
\text { part }\end{array}$ & $\begin{array}{l}\text { energy, } \\
\mathrm{GeV}\end{array}$ & TS flux & units \\
\hline $\mathrm{NE}^{(1)}$ & $1-2000$ & $\begin{array}{ll}28 & 6.14 \pm 2.53\end{array}$ & $10^{-12} \mathrm{erg} \mathrm{cm}^{-2} \mathrm{~s}^{-1}$ \\
\hline $\mathrm{SW}^{(1)}$ & & $13 \quad 0.88 \pm 0.24$ & \\
\hline $\mathrm{NE}^{(2)}$ & $0.5-500$ & $20 \quad 1.6 \pm 0.7$ & $10^{-10} \mathrm{ph} \mathrm{cm}^{-2} \mathrm{~s}^{-1}$ \\
\hline $\mathrm{SW}^{(2)}$ & & $23 \quad 2.0 \pm 1.0$ & \\
\hline
\end{tabular}

Table 4. GeV fluxes from the two parts of SN006.

\section{CONCLUSIONS}

In general, the fluxes from SNRs should not demonstrate any essential variation on the 10-year scale because it is small comparing to their ages. Only young SNRs might be expected to exhibit some variations. However, it was unclear what is the threshold age for a SNR when we may expect to see a variation of the GeV flux. Thanks to the Fermi observatory observations one can already say that Cas A, with the age of about 350 yrs, demonstrates an almost steady flux on the scale of ten years. 
In our paper

- the systematic analysis of the evolution of $\mathrm{GeV} \gamma$ ray fluxes from historical SNRs is presented;

- 10 yrs of observations are analysed (4FGL catalogue uses data from 8 years);

- the light curves are obtained for four SNRs with $T S>20$

- the observational data were analysed under the uniform approach for all SNRs, including the SN1987A region;

- the results of [12] for a (remaining) GeV flux from the region of SN1987A location are confirmed;

- our analysis of this flux shows an eventual break around year 2017 in its evolution; the pure quality of the data prevents us from excluding the purely statistical nature of the break;
- the GeV flux variations are compared with evolution in $\mathrm{TeV} \gamma$-rays, $\mathrm{X}$-rays, and radio range.

We hope that our results, as a systematic overview, might be useful for the time-dependent studies of evolution of the strong shocks and particle acceleration.

Acknowledgements. We are thankful to Denys Malyshev for giving us their .xml file for the analysis of the Fermi LAT observations of the region SN1987A; we used it for a cross-check of the results.

VM was supported by Polish NSC grant 2016/22/E/ST9/00061. MP acknowledges the support of the Astronomical Observatory of the Jagiellonian University for her International Summer Student Internship, where part of this work was done. This work was supported by the project 0118 U004941 funded by NAS of Ukraine.
[1] F. Aharonian et al., Astron. Astrophys. 370, 112 (2001); https://doi.org/10.1051/0004-6361:20010243.

[2] H. Abdalla et al., Astron. Astrophys. 612, A3 (2018a); https://doi .org/10.1051/0004-6361/201732125.

[3] H. Abdalla et al., Astron. Astrophys. 612, A8 (2018b); https://doi .org/10.1051/0004-6361/201730737.

[4] J. Albert et al., Astron. Astrophys. 474, 937 (2007); ht tps://doi.org/10.1051/0004-6361:20078168.

[5] J. Albert et al., Astrophys. J. Lett. 664, L87 (2007); https://doi .org/10.1086/520957.

[6] V. Acciari et al., Astrophys. J. Lett. 730, L20 (2011); https://doi .org/10.1088/2041-8205/730/2/L20.

[7] F. Acero et al., Astrophys. J. Suppl. 224, 8 (2016); http s: //doi .org/10.3847/0067-0049/224/1/8.

[8] G. Ferrand, S. Safi-Harb, Adv. Space Res. 49, 1313 (2012); https://doi.org/10.1016/j.asr.2012.0 2.004 .

[9] M. L. Ahnen et al., Mon. Not. R. Astron. Soc. 472, 2956 (2017); https://doi.org/10.1093/mnras/stx2079.

[10] M. Ackermann et al., Science 339, 807 (2013); https: //doi.org/10.1126/science. 1231160.

[11] S. Funk, Ann. Rev. Nucl. Part. Sci. 65, 245 (2015); http s://doi.org/10.1146/annurev-nucl-102014-022036.

[12] D. Malyshev, G. Pühlhofer, A. Santangelo, J. Vink, preprint arXiv:1903.03045 (2019).

[13] A. K. Carlton et al., Astrophys. J. Lett. 737, L22 (2011); https://doi .org/10.1088/2041-8205/737/1/L22.

[14] W. B. Ashworth, Jr, J. Hist. Astron. 11, 1 (1980); https : //doi .org/10.1177/002182868001100102.

[15] F. Gök, T. Ergin, Adv. Space Res. 56, 1793 (2015); ht tps://doi.org/10.1016/j.asr.2015.07.018.

[16] Y. Yuan, S. Funk, G. Jóhannesson, J. Lande, L. Tibaldo, Y. Uchiyama. Astrophys. J. 779, 117 (2013); https:// doi.org/10.1088/0004-637X/779/2/117.

[17] F. Giordano et al., Astrophys. J. Lett. 744, L2 (2012); https://doi.org/10.1088/2041-8205/744/1/L2.

[18] Y. Xing, Z. Wang, X. Zhang, Y. Chen, Publ. Astron.
Soc. Jpn. 71, 77 (2019); https://doi.org/10.1093/pa $\mathrm{sj} / \mathrm{psz} 056$.

[19] S. Abdollahi et al., Astrophys. J. Suppl. 247, 33 (2020).

[20] F. Aharonian et al., Astron. Astrophys. 488, 219 (2008); https://doi.org/10.1051/0004-6361: 200809401.

[21] A. Abramowski et al., Science 347, 406 (2015); https: //doi.org/10.1126/science.1261313.

[22] A. Abramowski et al.; Mon. Not. R. Astron. Soc. 441, 790 (2014); https://doi.org/10.1093/mnras/stu459.

[23] V. A. Acciari et al., Astrophys. J. 714, 163 (2010); http s: //doi .org/10.1088/0004-637X/714/1/163.

[24] F. Acero et al., Astron. Astrophys. 516, A62 (2010); ht tps : //doi .org/10.1051/0004-6361/200913916.

[25] P. L. Nolan et al., Astrophys. J. Suppl. 199, 31 (2012); https://doi.org/10.1088/0067-0049/199/2/31.

[26] A. Fruscione et al., Chandra News 14, 36 (2007).

[27] P. Freeman, S. Doe, A. Siemiginowska, Proc. SPIE, 4477, 76 (2001). https://doi.org/10.1117/12.447161.

[28] K. A. Frank, S. A. Zhekov, S. Park, R. McCray, E. Dwek, D. N. Burrows. Astrophys. J. 829, 40 (2016); https: //doi.org/10.3847/0004-637X/829/1/40.

[29] D. Patnaude, J. Vink, J. M. Laming, R. Fesen, Astrophys. J. Lett. 729, L28 (2011); https://doi.org/ 10.1088/2041-8205/729/2/L28.

[30] S. Katsuda et al., Astrophys. J. 723, 383 (2010). https: //doi.org/10.1088/0004-637X/723/1/383.

[31] J. F. Helmboldt, N. E. Kassim, Astron. J. 138, 838 (2009); https://doi.org/10.1088/0004-6256/138/ $3 / 838$.

[32] D. Reichart, A. Stephens, Astrophys. J. 537, 904 (2000); https://doi .org/10.1086/309073.

[33] J. Dickel, S. Spangler, Astron. Astrophys. 79, 243 (1979).

[34] S. Orlando, M. Miceli, M. L. Pumo, F. Bocchino, Astrophys. J. 810, 168 (2015); https://doi.org/10.1 088/0004-637X/810/2/168.

[35] M. Ackermann et al., Astron. Astrophys.586, A71 (2016); https://doi.org/10.1051/0004-6361/201526 
920.

[36] G. Zanardo et al., Astrophys. J. 710, 1515 (2010); http s://doi .org/10.1088/0004-637X/710/2/1515.

[37] Y. Cendes, B. M. Gaensler, C. Y. Ng, G. Zanardo, L. Staveley-Smith, A. K. Tzioumis, Astrophys. J. 867, 65 (2018); https://doi .org/10.3847/1538-4357/aae261.

[38] S. Orlando et al., Astron. Astrophys. 622, A73 (2019); https://doi.org/10.1051/0004-6361/201834487.

[39] J. Larsson et al., Astrophys. J. 886, 147 (2019); https : //doi .org/10.3847/1538-4357/ab4ff2.
[40] Y. Xing, Z. Wang, X. Zhang, Y. Chen, Astrophys. J. 823, 44 (2016); https://doi.org/10.3847/0004-637X/ $823 / 1 / 44$.

[41] B. Condon, M. Lemoine-Goumard, F. Acero, H. Katagiri, Astrophys. J. 851, 100 (2017); https ://doi.org/10. 384 7/1538-4357/aa9be8.

[42] O. Petruk, T. Kuzyo, F. Bocchino, Mon. Not. R. Astron. Soc. 419, 608 (2012); https://doi.org/10.1111/j.13 65-2966.2011.19722 . x.

\title{
КРИВІ БЛИСКУ ЗАЛИШКІВ НАДНОВИХ У ГАММА-ПРОМЕНЯХ ІЗ ГеВНИМИ ЕНЕРІІЯМИ
}

\author{
О. Петрук ${ }^{1,2}$, В. Бешлей ${ }^{1}$, В. Марченко ${ }^{3}$, М. Патрій ${ }^{4}$ \\ ${ }^{1}$ Інститут прикладних проблем механіки і математики, \\ вул.Наукова 3-Б, Лъвів, 79060, Украӥна \\ e-mail: beshley.vasyl@gmail.com \\ ${ }^{2}$ Астрономічна обсерваторія Лъвівсъкого націоналъного університету імені Івана Франка, \\ вул. Кирила і Мефоділ 8, Львів, 79005, Україна \\ ${ }^{3}$ Астрономічна обсерваторіл Ягеллонсъкого університету, вул. Орла 171, 30-244 Краків, Полъща \\ ${ }^{4}$ Фізичний факулътет Лъвівсъкого національного університету імені Івана Франка, \\ вул. Кирила і Мефодія 8, Львів, 79005, Украӥна
}

Високоенергетичне електромагнітне випромінювання породжується електронами та протонами високих енергій. Гамма-спостереження залишків наднових (ЗН) прямо вказують на те, що ударні хвилі в цих космічних об'єктах прискорюють космічні промені (релятивістські заряджені частинки) до енергій, вищих принаймні за десятки ТеВ. До того ж існують спостережувані ознаки часової еволюції гамма-спектрів ЗН на шкалі часу їхнього життя: виглядає, що форми спектрів від молодих ЗН, ЗН середнього віку та старих ЗН подібні в межах цих груп та відрізняються поміж групами. Часова еволюція гамма-випромінювання від молодих оболонок ЗН може дати важливу інформацію про особливості фізичних процесів, що супроводжують нестаціонарне прискорення частинок на фронтах сильних ударних хвиль. Ефективність прискорення залежить від швидкості ударної хвилі, а в залишках наднових, які спалахнули порівняно недавно, вона найвища. У статті проаналізовано дані спостережень таких об'єктів гамма-обсерваторією ім. Фермі, яка спостерігає випромінювання в діапазоні енерггій 0.1-100 ГеВ. Метою дослідження є виявлення характеру еволюції гамма-потоків від молодих ЗН. Проаналізовано випромінювання оболонкоподібних залишків віком до 1000 років: SN1987A, G1.9+0.3, Cas A, ЗН Тихо, Кеплера та SN1006. Оброблено спостереження в межах однорідного підходу, що дозволило взаємно порівнювати потоки від різних об'єктів. У підсумку залишків G1.9+0.3 та наднової Кеплера в ГеВному гамма-діапазоні детектовано не було. Криві блиску Cas A та ЗН Тихо не виявляють суттєвих змін потоку впродовж останніх десяти років, що узгоджується з подібною поведінкою їхнього рентгенівського та радіовипромінювання. Обговорено також статистично менш значущі потоки з ділянок розташування залишків SN1006 і SN1987A.

Ключові слова: залишки наднових, гамма-випромінювання, криві блиску. 